\title{
Sustaining Community Access to Technology: Who should pay and why!
}

\author{
Vanda N. Rideout \\ University of New Brunswick < vrideout@unb.ca >
}

Andrew J. Reddick

National Research Council Canada; University of New Brunswick < areddick@nbnet.nb.ca >

\begin{abstract}
Based on research on several national, regional, local projects, and on an analysis of the Canadian federal governments' main Internet public access programs, the authors argue that as the digital divide has evolved and changed, changes in a conception of this and approaches to sustainability are required. This requires defining sustainability in terms of supporting community organizations that provide social development and related content and services to the public, with support for core services, content development as well as technical access and networking. The authors further argue that governments, and in particular the federal government, has the primary role for providing sustainability funding at the community level to address the digital divide and development goals.

A conceptual approach is required that extends our understanding of the problem of the digital divide and sustainability to the everyday lived circumstances and needs of citizens and their local communities. Such an approach also permits us to consider sustainability as being primarily a responsibility of governments to provide funding to community service organizations providing services at the community level as a means of addressing inequalities and social and economic under-development. Funding should be used for technical services, the development and maintenance of core operations (staff, volunteers, overheads) and content services that can be accessed using communication technologies.
\end{abstract}

\section{Introduction}

During the development of Canada's 'publicly' accessible Internet throughout the past decade, the term 'digital divide' has been assigned many different meanings. These include ideas of a digital divide concerned with issues of technology access and affordability, technology as a primary means of individual or community development, geographical access, and constructions of different types of community (virtual, interest, geographic, and the technology infrastructure of communities).

Community research on technical issues relating to the digital divide tends to focus on community networks as a centralizing and coordinating communications infrastructure. A subset of this literature is research on the technology tools relevant to the digital divide and citizen participation with the objective of expanding communication channels towards satisfying basic information needs, promoting economic opportunities, and encouraging citizen access, among others. Analysis in this area generally remains at the level of identifying technical and skills difficulties affecting access (Pigg, 2001, p. 516-7). Moreover, these 
efforts have been limited in responding to a broader set of community needs, often because they have failed to produce or reproduce relevant community information resources, beyond community directories and basic information. As well, while there is much ado about online democratic discussion, these aspects of community networking and public access services are often not well developed (ibid, p. 519, 522).

Other Community Informatics research has been concerned with ideas of non-spatially based communities. Concerned with ideas of virtual communities or communities of interest, these studies have investigated the potential for people to create relationships and communities of interest which are not grounded in geographical space, thereby reducing the importance of geographic communities and local socio-economic conditions and relations (Wellman and Gulia, 1998).

Research on community networks that employ social capital theory have used the concept to assist, or create, economic, social and political development. Key issues here involve linking information resources, providing venues for participation, building community relationships, and so forth. An underlying theme of this stream of research is that community communication networks should reproduce existing social networks and resources, with the assumption that this will successfully, or more successfully than other means, realize various forms of community development (Pigg, 2001, 510; Gurstein, 1998). Others suggest that Community Informatics initiatives can only be sustained through community network adaptation and development. This means that community organizations have to find innovative ways within the community for funding and for human resource renewal (Page and Scott, 2001, p.549-51).

This paper is primarily based on the research of the two authors. Dr. Reddick was a co-investigator on a series of studies on the information highway and the digital divide with Ekos Research Associates Inc., including an evaluation of the Canadian federal governments' Community Access Program. ${ }^{1}$ Dr. Rideout ${ }^{2}$ conducted community digital divide research on twelve communities in Atlantic Canada, and is currently in the final stages of completing two case studies on community digital divides. The research conducted for this paper relies on information from these various studies by drawing on data from surveys, focus groups, in-depth interviews, and site visits.

The first section of the paper analyzes the major government funded community digital divide programs that have been pursued on a national basis. The second section provides a summary of the impact of these programs on selected community organizations and the services they provide. This section also considers the importance that community organizations are placing on broadband infrastructure to overcome emerging and continuing community digital divide problems. The final section provides the authors conclusions and recommendations about sustainability.

\section{Canadian Government Response to the Digital Divide}

\section{Community Access}

There have been numerous municipal, provincial and national initiatives to provide community access to the Internet over the past decade. The more significant of these, because they are national in scope, are the Community Access Program (CAP) and the Community Learning Network (CLN) program.

\footnotetext{
${ }^{1}$ The studies in which Dr. Reddick was a co-investigator include the Canadian Communication Household (1997); Rethinking the Information Highway series (1998 - 2003); the Dual Digital Divide series (Reddick et al, 2000 and EKOS 2001-2004) - principal investigator; and Evaluation of the Community Access Program (2001).

2 The studies in which Dr. Rideout was the principle researcher include "Bridging the Digital Divide in Atlantic Canada: Public Access to the Internet and the Canadian Digital Divide", Human Resources Development Canada - Office of Learning Technologies. www.nald.ca (full text documents) http://people.unb.ca/ vrideout; "Public Access to the Internet and the Canadian Digital Divide," Canadian Journal of Information and Library Science, 2000, 25 2/3; and "Digital Inequalities in Eastern Canada," Canadian Journal of Library Science, 2002/3, 27, 2.
} 
One of the most active federal departments addressing digital divide issues at the community level has been Industry Canada. The aim of this Department's 'Connecting Canadians' initiative has been to make Canada the most connected country in the world. This initiative encompasses many programs and services that were primarily designed for public libraries, public schools, the voluntary sector, rural and remote communities, small businesses and First Nations schools, in the hope of encouraging Canadians' to use the Internet. From the federal government's point of view the Community Access Program (CAP) is an important cornerstone of the Connecting Canadians initiative. Essentially the program provides not-forprofit organizations such as educational institutions, public libraries, community centres, community freenets and municipal and territorial governments with funding for computers, Internet connectivity as well as training (Industry Canada, 2004a, p.iii). The program's main focus has been on closing the digital divide perceived as the gap between communities, and geographic areas at different socio-economic levels, to access information and communication technologies (ICT), and to use the Internet.

Commencing in 1994 CAP focused on rural and remote communities with populations of less than 50,000 . The program was expanded to include urban communities in December 1999. Approximately 5,400 sites were established in 3,200 rural and remote communities. Rural/remote sites are primarily located in public libraries $(46 \%)$, public schools (28\%), municipal government facilities (8\%), community-based facilities (13\%) and business sites (5\%). Approximately 3,800 urban sites were also established in similar public locations. It is important to point out, however, that 1,200 CAPs have since closed leaving, according to government reports, 8,000 active sites (Industry Canada, 2004a, p. iv). Anecdotal evidence, however, suggests that another 1,000 or more sites may have closed since the research for the report was conducted because of financial difficulties.

While CAP has changed over the past decade, so has the digital divide, and understanding this has important implications for people, communities and public policy. At the basic level of access from home, a digital divide has persisted in Canada since the 1990s and continues today (Figure 1). Internet access from the home grew from about one in four households (28\%) in 1996 to about two of three households $(67 \%)$ in 2003. An additional seven per cent of households reported having had home Internet access at some point in time, but have since dropped it (Reddick, Boucher and Groseilliers, 2000; Ekos, 2004).

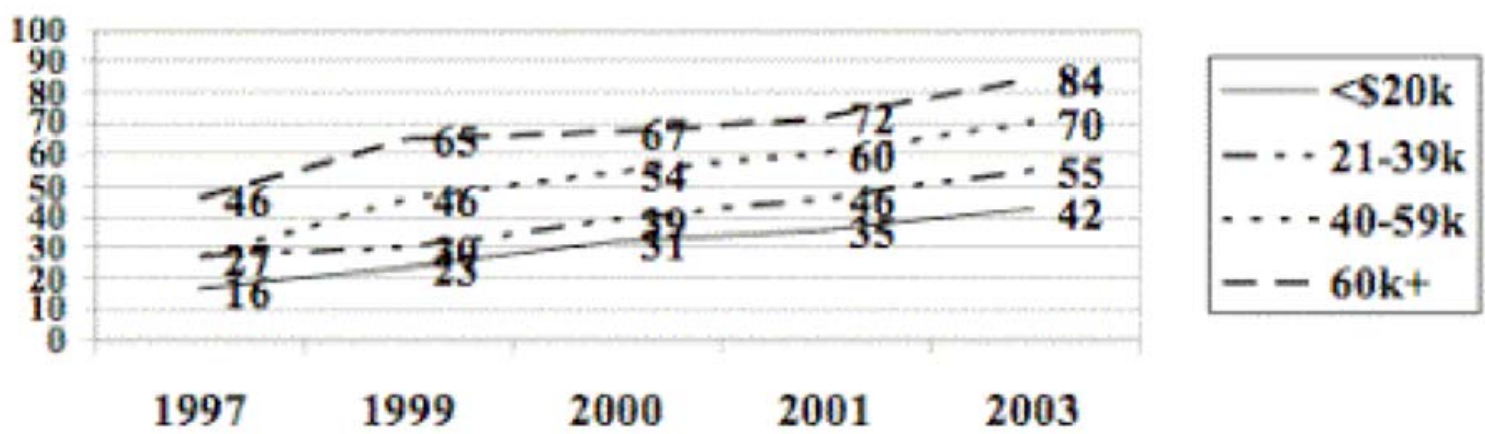

Figure 1: Individual Access from Home (Income) 1997-2003 (source: Ekos Research Associates Inc., 2001a, 2004)

This research shows that the reasons for both going and not going, online are complex. Socio-economic status has a major effect, but attitudinal/ experiential variables also matter, and these are closely linked to socio-economic status. However, more important is the very clear message underlying the respondent's views about the Internet and access, as revealed in the series of studies referred to in this paper. In this context, technologies are primarily understood as intermediary tools that are beneficial when they can be used to provide access to resources which meet people's needs (e.g., education, literacy, employment, and health information, etc.). And, it is these resources, and the organizations that provide them, that following this observation, might be understood to be most significant focus for a concern with sustainability (Reddick, et al, 2000). When considering the three main reasons cited for not going online, cost is a major factor for some, but also of importance are a lack of interest and a lack of perceived need (Reddick et al, 2000; Ekos 2001a, 2002, 2004). 
Those who cited cost as the main reason for not being online from home (Near users) were more likely to have lower confidence in technical skills, and were more likely to have an interest in, and see the benefits of, access than other non-users. Near users over the past few years as they have gone online, have been the main users of community access sites, and this group is expected to continue to account for the majority of the use of these sites in the near future. Near users tend to be younger (age 44 or less) and include many lower income, less educated Canadians who see potential education, employment and social benefits from Internet access. Respondents citing no interest in the Internet (Distant users) exhibited a lack of confidence in their technological abilities, a lack of experience with the Internet, were less likely to see practical uses or benefits from access, and were more likely to spend their free time elsewhere on leisure and entertainment activities. This group also requires assistance for access and training in order to go online at CAP sites. Those citing lack of need (Far users) as the main reason for not accessing the Internet do not see it as easy to use or convenient, nor do they see any benefits from use, and to a very limited degree, indicated a lack of experience as a final reason (Reddick, et al 2000: 42; Ekos, 2004). This typology of nonusers was characterized as a dual digital divide, with the first divide occurring between users and nonusers, and the second divide developing between the different types of non-users (ibid).

In recent research (Figure 2), of the twenty six per cent of Canadians who are not Internet users, the majority fall into the core non-user (Far user) category. These individuals have little interest or see little need in being online. Many of the Near users of a few years ago have gone online from some location. What is interesting now is that twelve per cent of non-users are now comprised of people who have used the Internet before and are likely to do so again. Also, sixteen per cent of non-users are 'drop-outs' or infrequent users. These are people who have used the Internet, but for a number of reasons have dropped this service. Translating these percentages into actual numbers, Statistics Canada estimates that in 2003 the number of Internet dropouts or infrequent users in Canada was 809,000 households, or 3, 236,000 people (Statistics Canada, 2004, p. 2).

Survey and focus group work conducted in the summer and fall of 2003 confirmed that publicly funded public access sites are still very much needed, and will continue to play an important role in addressing citizen and community needs. This research demonstrated that both public access sites and community networks play an important role for computer and Internet skills development and other skills and learning activities. These skills and learning needs are directly related to social class inequalities extant of the Internet, and addressing these is fundamental for individual and community economic and social development (Ekos, 2004). 


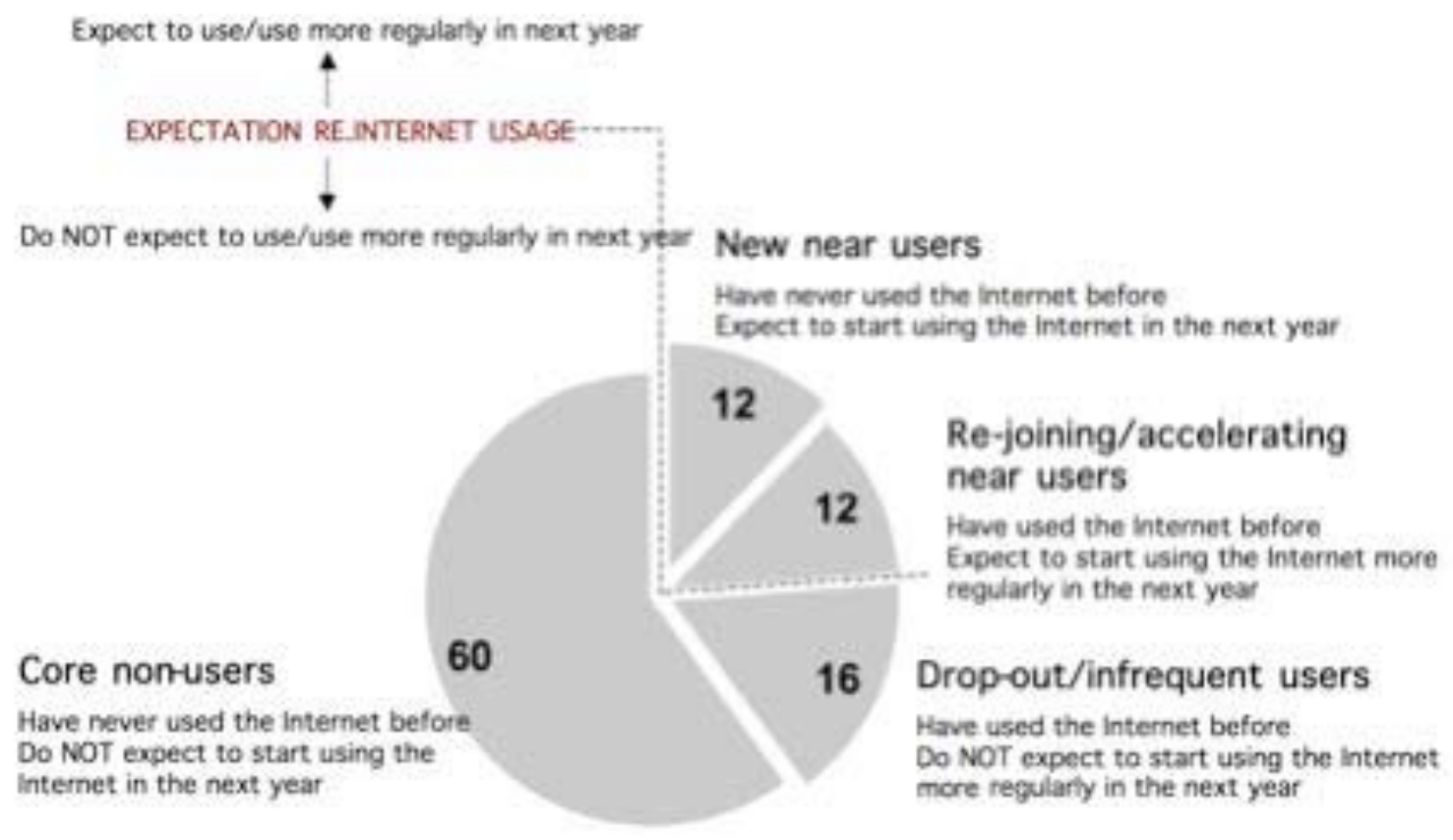

Figure 2. Internet Non-user Segmentation. BASE: Canadians indicating they have not used the Internet in the past three months (Internet uses); Apr/May, 2003, n=1360. (source: Ekos, 2004)

In particular, a significant minority of low income Canadians and labourers (those least likely to have access from work) may continue to rely on public access sites. Not having a computer or a computer that is too old have also become a significant barriers (due to cost) contributing to a continuing need for public access sites (Ekos, 2004: 86-87). This survey which is augmented with focus group research also found that current non-users, given the types of jobs they occupy (labour, blue collar) are unlikely to be able to develop computer and Internet skills at work, or be able to access the Internet from work. For example, in 2003 only seven per cent of those earning less than 20,000 dollars, and twenty five per cent of those earning between 20,000 and 39,000 dollars, had access to the Internet at work. Public access sites thus remain a useful resource to address the potential marginalization for these, and other, low income, low skilled Internet non-users. Longitudinal research (Ekos) on Internet and other communication technology usage of Canadians since 1997, demonstrates that the public use of access sites has remained relatively constant at seven per cent of overall Internet users, with about fifteen per cent usage for those with low incomes $(<\$ 20 \mathrm{k})$ and low skills and literacy $(54)$. In addition to indicating the continuing need to ensure the operation of such sites (and thus the need for sustainable funding), both the survey and focus group research indicated that information and services also must be made available through different channels such as print, mail, in-person, and phone as well as the Internet in order to accommodate the technical, literacy, privacy, geographical, and other capacities, limitations and concerns of the broad general public $(16,43,48,54,87)$.

The "Evaluation Study of the Community Access Program" by Industry Canada is the first publicly available report which evaluates the digital divide in rural and urban access sites. The study confirms the previously discussed findings (2004a). Questions were asked concerning the continued relevance of CAP, CAP program delivery and implementation, as well as the success and the cost-effectiveness of the program. The report concludes that the programs' initial objectives of raising public awareness of ICT and providing inexpensive public access to the Internet are now less relevant for some segments of the population. However, significant digital divide issues persist for low-income Canadians, those with little education, and those living in remote and northern areas. In addition, there remain areas and groups that have not been adequately reached even with existing programs including disabled peoples, First Nation peoples, northern communities, and the homeless, among others (Industry Canada, 2004a, p. 15-19). 
For those not online and others who will continue to rely on public access for some time, overall cost of access is the most important issue. As previously discussed CAP sites are most often found in libraries, community centers, schools, and not-for-profit public organizations relying on bare-bones funding. One of the criticisms identified in a survey of public access sites, conducted by Ekos Research for Industry Canada, is that the initial start-up funds provided by the program are unlikely to be sufficient to maintain services in the locations where these are most required, such as low income areas and rural/remote communities. At the same time, the report noted, many of the public access sites originally planned for CAP program beginning in 1996 have become less necessary as large number of Canadians have came online either in their homes or through their places of work. Barriers to long-term sustainability for the public sites as identified in the EKOS survey were the cost of purchasing or upgrading computers, a lack of staff and volunteers to operate the service, a lack of general operating funding, and the cost or lack of broadband service among others (Ekos, 2001b p. 28). Of those public access sites indicating that they had cut back on the services provided, the main reason indicated was a lack of funding, followed by a lack of staff/volunteers. Sustainable funding was also the major factor for the outright closing of a number of CAPs (29).

What this suggests concerning the matter of sustainable funding for these public access sites is that governments have a continuing role to play by providing direct financial support to maintain an access service level of appropriate quality. This same evaluation also found that it is not realistic to raise these funds from the private sector. Recent research demonstrates that there have been few positive results where such efforts have been undertaken and those companies involved, by and large, have not proven to be effective partners. As well, municipalities do not appear to be viable alternative sources of support as many have limited resources to support this kind of service (Ekos, 2001b; Rideout, 2002/3).

A number of problems and uncertainties continue to plague the CAP program. First, the original objectives of the programme included unrealistic goals that stretched funding by for example, including a requirement for Canadian content online. By including this requirement Industry Canada extended the program into areas which are the responsibility of the Department of Canadian Heritage. Although Heritage's mandate includes Canadian content neither it nor any other government agency offers any programs that CAP organizations could apply to for financial support for content development.

As well, although Industry Canada included electronic commerce and economic development within the 'Connecting Canadians' agenda these activities require sophisticated and high skill levels. However, the responsibility for skill development falls within the mandate of the Department of Human Resource and Skills and Development. This confusion and competition within the federal government over roles has not been helpful for either departmental activity or for supporting the development of the public information resources for which the CAP user community has a demonstrated need.

However, perhaps the most fundamental issue concerning the program is that with its narrow focus on technical access, computers and connections, it has largely excluded human and social needs. Of course, this was not the priority for the Industry Department and through CAP the government could be seen as doing something to promote the Internet and of course, from a purely logistical point of view, it was much easier to deal with the development of some 10,000 Internet access sites, than with several million Canadians along with the variety of their skill, literacy, affordability, and technical access challenges.

The last competition for rural CAP closed on May 31, 2000, and the final adjudication for the urban sites occurred on February 28, 2001. As noted in the previously cited report, the Department is no longer soliciting or considering new applications (Industry Canada, 2004b p. 2). Furthermore, a recent Industry Canada news bulletin highlights the new strategic direction that the program is taking. Funding has been reduced to $\$ 25$ million per year for 2004-5 and 2005-6. This reduced funding envelope is intended to cover not only the CAP financial contributions; but it also applies to Industry Canada's operating and salary costs for managing the program. The communiqué also notes a shift in program direction from general public access to support for digital divide communities and on-line government services (Industry Canada, 2004b). Moreover, the CAP network is scheduled to be downsized which may lead to the eventual unwinding of the Information Highway Application Branch (IHAB), the branch of Industry Canada that was created to help connect Canadians to the Internet. Although the communiqué discusses the success of 
the ten-year community access program it also explains that the government is going to 'step aside' from $\mathrm{CAP}$ in order to fund new programs such as the information technology component of the Voluntary sector, the francommunautés virtuelles, and the broadband initiative (ibid).

\section{Community Learning Networks}

Working within its mandate the Department of Human Resources Development Canada (HRSD) has focused on other information society barriers such as upgrading technology skills for the workforce and the use of learning technologies. In 1996 HRDC created the Office of Learning Technology (OLT) in order to increase the availability and sharing of information pertaining to learning technologies. In a recent policy document, the OLT explains that Canadians "need to become a nation of life-long learners, in addition to becoming the most connected country in the world" (OLT, 2003 p. 2). The primary objective of OLT's Community Learning Networks (CLN) program is its support of innovative and sustainable uses of existing technologies intended to strengthen the capacity of communities. The Office hopes to address the socioeconomic disparities that arise with the shift to a knowledge-based economy, as well as support the achievement of economic and social development goals (ibid).

The OLT considers the CLN program to be directed to reducing disparities between communities. This is supposed to be the outcome of an increasing development of workplace skills, particularly technology related skills; and by promoting an environment supportive of lifelong formal and informal learning. OLT explains that many Canadians still do not possess the necessary skills to engage with information and communication technologies and are not comfortable with computer hardware and software that are not user-friendly. The Department's programs are directed to addressing a number of social inequalities, though only on a short term basis (OLT, 2003).

To some extent, the Program does address the real needs of the public and community service organizations. For example, a community organization in Toronto that received OLT funding, conducted a community needs assessment and designed its technology program to meet the literacy, training, employment and community information needs of the local citizens and the overall neighbourhood, with the goals of individual and community development (PIAC, 2000). This community organization provides valuable services to the public addressing social and structural inequalities. However, once having made the very large investment in these pilot projects, sustaining the services over the longer term including the technologies, and the staff required to operate these is a major financial challenge. ${ }^{3}$

The CLN program defines community loosely as being geographic or interest based such as a designated neighbourhood with defined boundaries; a territory that corresponds to a local government jurisdiction; or a group with shared interests such as people with a common language, common values or common goals (OLT, 2003 p. 29). A key objective of the program is to support research and to test innovative approaches to help adult learners find and keep employment in a knowledge-based economy. However, such an objective is unrealistic, according to literature on the "information society", given the requirements in a knowledge-based economy, for a flexible and contingent workforce and for a constant expenditure on ever-evolving technology related skills and training (Rideout, 2002/3).

The 2004 call for CLN proposals, with a closing deadline of August 31, 2004, identifies those projects that it will consider including those concerning workers affected by the shift to a knowledge-based economy i.e., older workers; the people who are unemployed or underemployed; new immigrants, women and Aboriginals; as well as people with disabilities (HRSDC, 2004a).

Since 1998, OLT has funded approximately 100 CLNs. Under the new call for proposals the eligibility guidelines now apply to not-for-profit national organizations or associations with a mandate in the area of socio-economic development and/or learning (HRSDC, 2004b,c). Eligibility requirements include organizational capabilities and the necessity of forming partnerships which are intended to secure long term sustainability. Examples provided include support of employment-related services or programs in the

\footnotetext{
${ }^{3}$ Both authors were evaluators for applications for the CLN program and noted that consistently there were no viable sustainability options identified for after the initial CLN program funding.
} 
labour market, the use of technology to develop or deliver community best practice-based learning opportunities, the enhancement of the socio-economic conditions of applicants' communities and an increase in community clients' participation in the knowledge-based economy.

The maximum amount of funding assistance for CLN projects has increased from 250,000 to 400,000 dollars over a three year period. Proposal guidelines identify eligible costs such as salaries for people employed on the project, and ineligible costs as being the purchase or maintenance of technological infrastructure such as computers and related equipment, technical support and Internet access. This means that CLNs are expected to use existing networks and Internet connections by relying on the CAP or electronic networks at other organizations. It is also expected that project sponsors will have an established track record in developing or delivering community-based technology-assisted learning opportunities. Partnerships are highly recommended between the CLN and the voluntary sector, co-operatives, sector councils, band or tribal councils, labour or professional associations, provincial governments, municipal governments, libraries, schools, or federal departments or agencies (HRSDC, 2004b,c). However, our research indicates that these recommendations to program applicants are at best "wishful thinking" since they are not grounded in community reality. Once built, many of these community networks and their participant organizations do not have the financial resources to sustain them beyond the initial period of government support. These issues are even more acute since, in addition to the funding provided through this program, these organizations must also find funding for their on-going core activities in such areas literacy, training, community information, services or social and economic development.

OLT undertook a review of this program in 2003 and published a report that included discussions with community experts. What is interesting about the sustainability discourse in Policy Conversations on Future Directions for Community Learning Networks, is that community network applicants are being encouraged to establish ongoing community and monitoring tools (OLT, 2003). However, it is notable that the tools being suggested in practice conflate issues of financial sustainability with the evaluation information OLT requires for project review a project related to an assessment for government purposes of the community network's "success" or "failure". Although evaluation and record keeping are often required by the directors and board members of non-profit organizations, this management-by-systems approach provides the federal government with information about the possible viability of using the project as a model to be reproduced elsewhere. Notwithstanding that a successful CLN or OLT self-or program evaluation may translate into future grants from this or other government programs, the major issue of funding for community non-for-profit organizations remains outstanding. References to financial sustainability in the Policy Conversations Report combines traditional religious and business discourses indicating that as long as a community network has 'beliefs', 'faith', 'inspiration' and can develop community synergy it will be able to resolve the issue of sustainable funding. However, raising funds for the longer term survival of the community network and thus provide disenfranchised citizens with services and information requires continuing community events, more grant writing to philanthropic organizations, foundations, government agencies, and corporations (Kuttan and Peters, 2003 p. 174; Rideout, SSHRC data, 2002-4).

\section{Community digital divide sustainability}

What follows is a summary of the major research finding of on-going research on community learning networks and access sites located in the Atlantic region (Rideout, 2002/3, and preliminary SSHRC data). It is important to point out that many of these networks and some access sites were developed by existing community organizations that have been providing social and community development services for decades. For example, one community learning network has twenty years experience delivering a number of learning programs to youth, adults (transitional programming), seniors, as well as early literacy programs and family literacy training. Through one of its local partner organizations the CLN is linked to a forty year distance education service delivery program.

This background has influenced the assessment of community needs starting with objectives and goals geared to creating community capacity to encourage local people to engage with technologies. These technologies include community television, community radio and the Internet. Community capacity 
building relies on human and community capabilities by focusing on attaining and maintaining social and familial needs, as well as access to universal and affordable information technologies (Rideout, forthcoming). What the organization decided to do is bring the people to the technology rather than the other way around. This was done so that people could overcome any fears or concerns they might have about the technologies they would be operating. The manager of the learning network explained that some of the CAP sites remained idle for a number of years because they were housed in libraries and schools, places that a number of people in the province do not frequent. Certainly a level of frustration with the CAP and the CLN programs was best expressed as a "gap between the expectation of the government for what is to happen with the Internet and what the people want to do with it".

For the past twelve years this learning network has constantly tried to obtain foundation funding or applied to government programs for funding to keep the organization going. Other than the manager who works on a part-time basis services are provided by volunteer workers who, because of the amount of work they do, tend to "burn out". Past experiences with federal government funding has left the communities very sceptical about programs that only provide short-term solutions rather than sustainable funding.

A remote CAP site was established and operated through the 1990s as a way of getting technology funding. The CAP manager explained that such an approach tends to exhaust a community because they were always doing one project and hurrying to finishing it so they could apply for another project in order to secure financial resources to keep the site operational. Currently the site relies only on CAP funding to provide adult literacy and community economic development services. The other major service that the site provides is a monthly newsletter, produced to keep local residents informed about what is going on in the community. The site is also involved in a community mapping project using CAP computers and geographical information system (GIS) technology to identify a range of local human and natural assets.

A second CLN with organizational links to a maritime resource centre provides a number of community services to address civic, economic and social needs. These services are directed primarily to the adult population, particularly those people and organizations involved in the fishing and aqua-culture industries. These services include conflict resolution, organizational development, as well as proposal writing for grants. The most unique service the network provides is geographic information system (GIS) training for coastal mapping and marine topic information such as fish and shellfish stocks. The manager explained that,

the project was for three years, in our view successful, although the network that we visualized when we started didn't come about, just because the technology wasn't there. The ideas that we had for high-speed internet, that infrastructure existed in some communities, but you know, in most of the costal communities it wasn't there. It just wasn't good enough.

The heavy competition for sustainable financial government funding has forced this organization to seek support from foundations in Canada and the United States. Rather than compete for limited government funds the network has decided to seek support from 'the foundation treadmill.' Given the large number of community networks requiring sustainability support and the limits of funds from the foundation community, this is not considered by the authors to be a viable approach to long term sustainability for this, or other, community networks.

A community public library uses a mix of CAP computers and the local community broadband network to deliver its library services to patrons that are dispersed throughout the area. By going online to the library web site patrons can access their library account from home, place holds on items, and renew books at no additional charge. Additional resources have also been directed to train part-time librarians so that they cans provide rudimentary training on how to set up an e-mail account, how to search the Internet and how to use Power Point. Often librarians are asked to help patrons with e-government services such as the electronic forms now provided by HRDC (now HRSDC). HRSDC has been at the forefront of encouraging e-government services. Yet as the head librarian stated, often HRSDC and other government forms are "quite difficult, challenging and frustrating to use" for the patrons and the librarians who help them. 
Additional research conducted in two rural and remote communities in the Atlantic region indicated that accessing the provincial information highway networks was a major problem. In each case local organizations decided to build a community-oowned and managed broadband network. Justification for investing in high-speed systems was to provide local access that was affordable in order to meet specific community social and economic needs.

Hi-speed networks are an increasingly important issue because the cost of broadband risks putting the Internet further beyond the reach of those not yet connected. However, such networks also create new obstacles for those who have narrowband. For some, the cost of upgrading may be prohibitive. For those in rural areas, where broadband is not available or very expensive, the access divide gains an added dimension. Beyond the networking level, the broadband divide is being further aggravated by the ever expanding complexity and storage requirements of content, which in turn, increasingly requires more bandwidth and computer power for access and use. While nice to have, these wonderful, colourful, multilayered and interactive features, also slow down operations and use, and require users to be undertaking expenditures to maintain a suitable level of service quality.

Our recent survey determined that of those connected in Canada only a small majority now have broadband (Figure 3). The divide between those with high-speed and dial-up access is greatest between rural and urban households. Forty-three per cent of urban households as compared to nineteen per cent of rural households have broadband or high-speed. Comparable to overall Internet usage, low income, bluecollar employees and seniors/retirees are not only least likely to have household access, but are also less likely to have high-speed access from home. Regionally, over a quarter of Atlantic Canadian and Quebec (28 \%) households have high-speed access, with just over a third (39\%) in Ontario, and almost half (47\%) in Alberta and British Columbia. Where, about one in four low-income (less than $\$ 40,000 /$ annum) households have high-speed Internet, almost one in two middle and upper income (over \$60,000/annum) households have similar connectivity.(Ekos, 2004 p. vi, 75, 77, 78). These findings closely approximate those of Statistics Canada, (2004 p. 2). But as previously indicated the relevance or importance of a broadband digital divide is linked to community/individual needs, practices and resources (Ekos, 2004). 


\section{Type of household Internet access}

Q: What type of Internet access is there in your household?

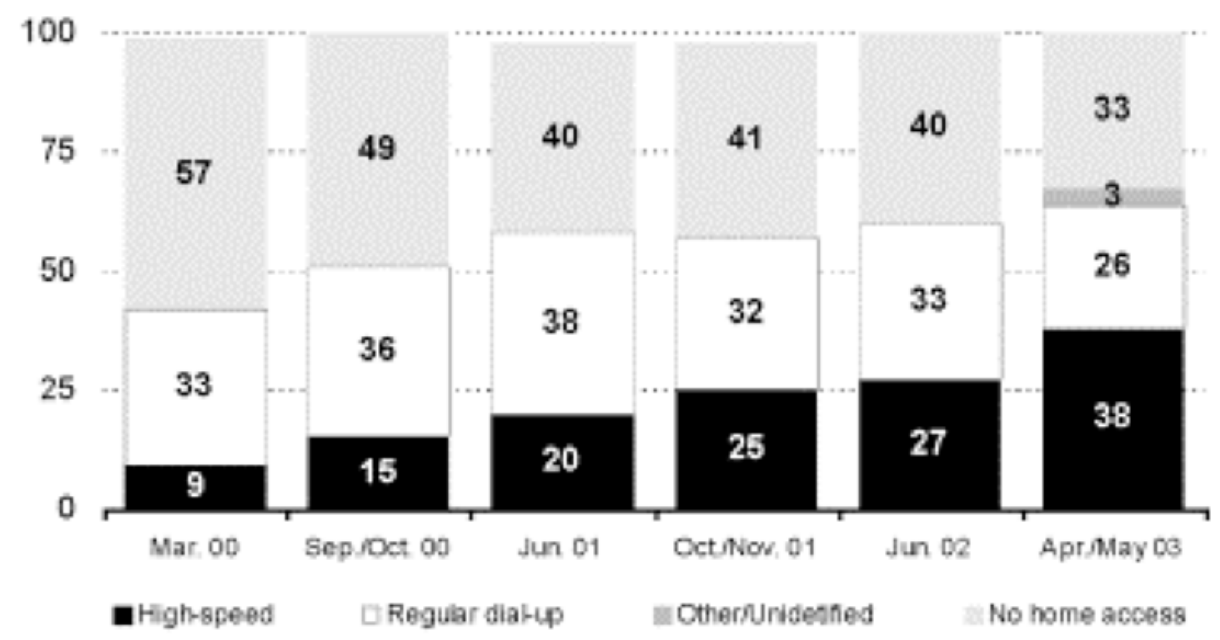

Figure 3: Type of Household Internet Access (source: Ekos, 2004)

A community organization in a remote Newfoundland out-port has built a broadband network so that video conference technology can be used to receive affordable distance secondary education and health services. These efforts were to address underlying community social and structural inequalities that range from low levels of education and high illiteracy rates to inadequate emergency health care services. The project involved interconnecting five fiord or island communities. One of the main issues that had to be addressed was affordability and sustainability (including network, computers, staff, facilities, etc.). Although a tele-satellite model was considered it was rejected by community interests as too expensive ( $\$ 100.00$ per hour) for continuing video-conferencing service.

In addition, the community was told by the incumbent telecommunications and Internet server provider that a business case could not be made to extend the company's infrastructure because of geographic constraints. Although information society analysts maintain that the new networks are able to span geographical barriers this was not the case for this community (Cairncross, 1997). The service provider informed the organization that the network could not reach their community because of expanses of water and 600 to 1000 foot rock cliffs. As one community member said,

there was really no way in God's green earth you were ever going to convince NewTel to run a fibre-optic cable 150 kilometres through the middle of nowhere to a community of less than 1,000 people.

However, with start-up funding from the Atlantic Canada Opportunities Agency, Human Resources Development Canada, the provincial education and health sectors, local individual subscriptions, and fulltime network technical support the community solved the technical challenge and have constructed a 
wireless community broadband network. Monthly charges paid by institutional, business and residential subscribers have proven to be affordable.

While funds were raised to build the broadband network, continuing financial resources are required to maintain and staff the organization. Additional funds are also required for network expansion so that it can connect to the provincial cable broadband backbone.

A community broadband network in Nova Scotia was built so as to foster community capacity building and strengthen the ability of its individuals to work more effectively with community organizations, to help community development, and to address the lack of communication infrastructure in the area. A regional development organization was successful in winning a federal government competition for a 'smart community' (Industry Canada, 1998). The most significant project the smart community has undertaken is to build a 26 kilometre $\$ 1.4$ million fibre optic backbone network. Member groups and other funding sources including Industry Canada, a branch of Canarie called ACORN, HRDC, and provincial and municipal governments provided matching funds included as part of the total grant.

This community broadband network has also been constructed to provide affordable broadband services to the area. The original partnership talks that occurred with the incumbent telecom ISP broke down because the company claimed that it would fast-track digital single line (DSL) technology to the region but it wouldn't reach as many communities as originally thought. When the community organization ended the partnership only 6 per cent of businesses and residents had access to DSL. This meant that the other 94 per cent of population could only obtain access to the digital line by paying from $\$ 3,000$ to $\$ 5,000$ per month.

A community-based consortium (seven municipalities and a community college) developed and managed the broadband network in partnership with a small private cable company. Phase two of network development includes using a mix of wireless and fibre network technology to reach other remote areas with the hopes of connecting to the provincial internet backbone and the largest city in the Maritime region, Halifax.

When queried about the frustrations and problems the organization experienced with the Smart Community Program a number of issues were raised. First, the program was prematurely implemented. Second, the program was not always clear about what it expected or wanted from the community. Third, Industry Canada's requirements for the program continuously shifted, resulting in wasting of time and other resources. Finally, Industry Canada forgot to exclude the Department's financial costs from the total grant for the operation of the program. It should also be noted that neither the Nova Scotia broadband network nor the one located in Newfoundland obtained any funding from the broadband access program (Industry Canada, 2001).

These examples reinforce the primary reason why the federal government should provide on-going sustainable funding to the community organizations that provide access and learning networks. These are directly related to the services and information being provided to local citizens as public goods intended for overall social and economic development and betterment. These services include improving education levels, upgrading literacy, community health services and information, and job training for the unemployed. Some community networks produce their own local content as a means to promote and preserve local culture and heritage. Other community organizations provide value-added services and information using geographical information system technology for coastal mapping. Conceptually, these findings help convey a deeper understanding of what the community digital divide is all about.

The federal government has promoted the private sector as the way to develop and provide information highway related services to all Canadians. However, as shown elsewhere, the private sector has only provided these services where it is most profitable (Rideout, 2003). In contrast, the type of services and content the public values the most is primarily social and non-commercial in nature.

Our survey and site research found consistently that the types of information and services of most interest to the public involved content or activities linked to everyday needs, such as finding a job, health 
information, accessing public information resources, learning or skills activities, and literacy training. This points to one of the key issues of financial sustainability, that much relevant social information is produced by, or accessed through, community organizations and made available to the public through a variety of media. In extending the concept of the "digital divide" to that of a "community divide" it is important to not lose sight that a variety of methods are employed by community organizations to provide community resources and to address social inequalities (Rideout, 2002/3; Ekos, 2004).

In addition, with an increasing offloading information and service delivery to communities by federal and provincial governments, local organizations are now required to provide traditional and new services/information. As well, local organizations are required to provide information and services using information and communications technologies (ICTs), particularly the Internet. Finding financial resources to sustain general operations and human resources for these organizations, as well as for traditional channels and the Internet has become an important issue. For Internet users and non-users, it is not the technology that matters most, but how their social needs can be met including the range of media. (Ekos, 2004).

Using access to government information as an example as indicated in Figure 4, Internet users and non-users, though varying in degree, prefer and rely on different channels to meet the full constellation of their every-day information needs.

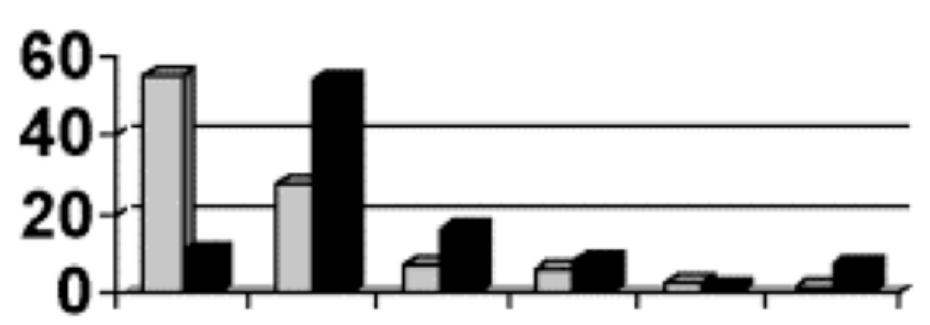

Figure 4: Method of contact in future - Government service. 2003, n=2,113 (source: Ekos, 2004)

Survey research demonstrates that the type channel used by the public depends on a number of factors, including trust in the organization or individual involved in the communication, confidentiality of the information, importance of timeliness of a transaction, the type of information or service involved, availability of technology, geographical relevance of the information/service (e.g., local, provincial etc.), ability to use a technology, and affordability (Ekos, 2004). This adds another dimension to sustainability for community organizations. In addition to funds for online service, they also require an adequate and consistent level of funding to maintain quality levels of service with the other communications channels.

While the federal government has been pushing the Internet as the main channel for information and service delivery, it has recently encountered resistance. For example, the government convened an Advisory Panel to help develop its Government Online strategy in 2000. The panel members, made up of representatives from civil society, rejected the governments' proposed Internet-only service delivery approach and, instead, strongly recommended that a multi-channel approach be adopted as a matter of policy to ensure that the needs and capabilities of all Canadians were accommodated. It would appear that this recommendation to shift back from the Internet-only view to a multi-channel approach has been acknowledged, at least in discourse, by the federal government's Connecting with Canadians: Pursuing Service Transformation, the final report by the Government On-Line Advisory Panel (Canada, 2003, 6). Whether the federal government implements such a recommendation remains to be seen. While hundreds 
of millions, if not billions, of dollars have been allocated by the federal government for Internet service delivery, it appears that no significant amounts of new monies have been identified for other channels.

Because the CAP perceived the digital divide in technological terms it ignored long term sustainability. In contrast, the CLN program is largely concerned with human needs, skills and social participation, and using networking to enhance these. The CLN program is, however, presumptive about technology, assuming it is available by means other than through their support, and that the program will deliver on its promises of ubiquitous access for all, and relevant to all needs. In common with CAP the CLN creates a new funding obligation for the community participants, but offers nothing in support of ongoing sustainability such as financial support for core services, user training or community content development, etc.. Our research reveals that in addition to community organizations constantly searching for sustainability funding for their organizational and core programs to provide employment training, literacy training, health and community services, etc., a new layer of funding and resource challenges are required for Internet access and community networking initiatives. This creates an increasingly untenable situation whereby both core activities as well as new ICT-based activities are in competition for limited government funding. As such, both core operations and, CLN and CAP initiatives could be put at risk. This problem is further aggravated because government funding that is available for both types of activities (core and ICT related) tends to be short term, lasting three years or less. The core services provided by the community organizations such as education, literacy and employment training can take years to achieve meaningful results, while health and social services delivery are ongoing. As well, it also takes several years to develop a mature community communications infrastructure (Rideout, 2003).

The services and information provided by community organizations such as learning networks, access sites, health centres to local citizens have a major impact on community technology sustainability. Our research demonstrates that this is because money, staff, volunteers and, materials and supplies are required to create and provide information and other services to meet the specific needs of people in the communities. Moreover, these must be continually updated as demands and user profiles change.

\section{Conclusion}

As this paper has discussed, a community digital divide is grounded in social practices and existing inequalities along with the lack of sustainable access to information and communication technologies and network infrastructure. Evidence from our research based on surveys, interviews, focus groups and site visits to various community organizations indicates that the major problem for these organizations concerning the digital divide is one of financial sustainability. Financial sustainability includes the support for those activities and resources essential for relevant, meaningful and successful participation in every day life of people who live in geographic communities throughout Canada.

This research has also demonstrated that a conception of a community digital divide holds particular importance because the information and services provided by community organizations, and used and demanded by the public, are concerned with important needs and skills that address social inequalities and development goals. Financial support (sustainability) is required for community organization's core operations, community content development, technology services, as well as multi-channel information and service delivery to accommodate all citizens' needs and capabilities. As part of core operations, sustainability funding is needed by organizations for operating overheads and to hire full time staff. Most organizations are run by one or a few full-time staff, with the balance drawn from volunteers, summer students and part-time workers. Survey and focus group research has provided evidence that there is a continuing need for public access sites for specific social sub-groups and sustainability funding is required for those sites that meet this need. In addition to basic access, site research revealed that there is a community level need for sustainable broadband service, particularly in rural and remote areas. The research has also demonstrated that most of the core funding for these community organizations is from government programs and foundation grants, as well as projects they are able to engage in at the local level. All the government programs are very competitive, and success is not assured for the organizations. Moreover, current funding programs from government are short-term in nature. 
While we agree with the research noted above, that has been done on community networking, in our view alternative ways of sustaining community access to technology and networks requires long term government funding. In our view, this is primarily a government responsibility because community access and networking involves the delivery of, and access to, public information and services. Our entry point for analysis is that the digital divide is grounded in social practices and inequalities at the local level; therefore it is a community digital divide. By this is meant that the digital divide should be defined as the gap that exists in access at the community level to information and communication technologies and networks, and as well taking into consideration existing social inequalities and the quality of community social services. ${ }^{4}$

Social practices and inequalities are needs-centric and are concerned with community and individual development goals. As the digital divide has evolved over the past several years, approaches in response to the digital divide should include sustainability funding for access to technology at the community level. In our view, the digital divide (community/individual access, etc.) should be conceptualized so as to recognize its role in aggravating the ability for communities and individuals to address long-standing and more deeply entrenched social needs, inequalities and developmental challenges, particularly as we move further into the realm of an information society. By doing so our understanding of the digital divide and approaches to sustainability are enriched to include questions of who should pay and why. Community and individual developmental activities are, and have traditionally been, dealt with through public policy because they concern the general public interest. In this regard, we argue that, a priori, the most logically consistent means for the sustainability of the various community initiatives to address digital divide problems is derived from government funding.

Our use of the term 'inequalities' refers to social and economic inequalities which are the products of uneven regional development and class based social stratification. Regional (rural/remote, provincial, etc.) disparities in Canada largely arose from a century of national economic policies which centralized economic planning, production and marketing. This has resulted in many provinces and communities having under-developed social and economic infrastructures. Many communities and some provinces also have an over reliance on the resource sector (e.g., agriculture, fishing, mining, lumber), with lower levels of income, education and health services compared to other parts of the country (Brodie, 1990). These types of disparities are not unique to rural or remote areas, however.

Our research demonstrates that these same kinds of problems also exist in smaller communities within successful provinces, and in neighbourhoods within large urban centres. Social and economic inequalities for individuals are based on the capitalist nature of our market economy and society. What this means is that the structural aspects of our market economy creates differential levels of income, education, literacy, public services, and employment among others. Ongoing government intervention, using such policy tools as financial redistribution and social services (e.g., schools, hospitals, etc.) are essential to mitigate these social relations, and to provide opportunities for individuals and the communities in which they live to overcome these inequalities (Clement, 1991; Rideout, 2002/3). Community organizations play an important role in these activities because they provide many of the social services and act as gateways to government services. When we discuss the need to re-conceptualize and extend the meaning of the community digital divide through the of use of technologies as tools or resources to address inequalities, we are doing so based on an assumption of the use of these as entry points.

By returning to the subtitle of the paper 'who should pay and why' for sustaining community access to technology the answer, as we have discussed, is obvious. Local organizations are delivering community and government services to citizens. These include education, skills training, literacy training, health information and services, among others. By and large, these are public services, providing general social and individual benefits. As such, there is an obligation to use public funds to support these. It is governments at the municipal, provincial and federal levels that have primary responsibility to deliver

\footnotetext{
${ }^{4}$ Using technology as an entry point, risks reducing the reasons people use technologies to subordinate analysis or abstraction. Kling (2000), in a useful discussion on Social Informatics, notes that in analying information technologies and how they are used in institutional and cultural contexts, it is important to avoid the risk of theoretical and methodological slippage whereby one frames technology as determining of the social (e.g., the Internet will solve employment, education, health problems, and so forth) (218).
} 
funding and other forms of support. This is exactly the same as they have done for the past 100 years or more to sustain an evolving basket of public goods.

Without this kind of support, information and services required by citizens will not be sufficient, effective or sustainable. The authors conclude that sustainability involves long term as opposed to shortterm government support.

\section{Acknowledgement}

Dr. Rideout acknowledges financial support from two SSHRC grants for a portion of the research discussed in this paper. 


\section{References}

Brodie, J. (1990). The Political Economy of Canadian Regionalism. Toronto: Harcourt, Brace, Jovanovich.

Cairncross, F. (1997). The Death of Distance. Cambridge, MA: Harvard Business School.

Canada. (2003). Connecting with Canadians: Pursuing Service Transformation. Final Report of the Government On-Line Advisory Panel. Ottawa, Canada.

Clement, W. (1991). The Challenge of Class Analysis. Ottawa: Carleton University Press.

Ekos Research Associates Inc. (2004). The Dual Digital Divide IV. Ottawa: Ekos Research Associates Inc.. (2002). Tracking the Dual Digital Divide. Ottawa: Ekos Research Associates.

(2001a). Rethinking the Information Highway: Rethinking the Dual Digital Divide. March 30. Ottawa: Ekos Research Associates Inc..

(2001b). "Evaluation of the Community Access Program: Census of Sites." Final Report Submitted to Information Highway Application Branch, March 31. Ottawa: Ekos Research Associates Inc..

(2000). The Information Highway and the Canadian Communication Household. Ottawa: Ekos Research Associates Inc..

Gurstein, M. (1998). "Information and Communication Technology and Local Economic Development", in Perspectives on Communities: A Community Economic Development Roundtable, Gertrude Anne Macintyre (Ed), 159-182.

Human Resources and Skills Development Canada. "Community Learning Asset Mapping: A Guidebook for Community Learning Networks." Office of Learning Technologies. (Accessed: July 8, 2004 a: http://www.hrsdc.gc.ca)

(2004b). Community Learning Networks Initiative. (Accessed June 5, 2004: www.hrsde.gc.ca last modified 2004-03-30)

(2004c). Guidelines for Pilot Project Proposals - 2004 Office of Learning Technologies Community Learning Networks. (Accessed: July 8, 2004: www.hrsdc.gc.ca)

Industry Canada (1998). Smart Communities: Report of the Panel on Smart Communities. Ottawa, Information Distribution Centre, Industry Canada. Available: http://smartcommunities.ic.gc.ca

(2001). The New National Dream: Networking the nation for broadband access. Report of the National Broadband Task Force. Ottawa: Information Distribution Centre, Industry Canada

(2004a). "Evaluation Study of the Community Access Program (CAP)". Final Report, Audit and Evaluation Branch, January, 16. (Accessed: June 5 2004: www. Industry Canada.gc.ca)

(2004b). "2004 Budget Update - Changes to the Community Access and SchoolNet Programs." (Accessed: July 8 2004: http://ihab-transition-dgaai.ic.ca/pub/index.html?iin.lang=en)

Kling, R. (2000). "Learning About Information Technologies and Social Change: The Contribution of Social Informatics". The Information Society. 16, 3: 217-231.

Kuttan, A. and L. Peters (2003). From Digital Divide to Digital Opportunity. Lanham, Maryland: Scarecrow Press. 
Office of Leaning Technologies (2003). "Policy Conversation on Future Directions for Community Learning Networks." (Accessed: July 8, 2004: www.hrsdc.gc.ca)

Page, M. and A. Scott, (2001). "Change Agency and Women's Learning: New practices in community informatics", Information, Communication \& Society, 4-4, 528-559.

Pigg, K. (2001). "Applications of Community Informatics for Building Community and Enhancing Civic Society". Information, Communication and Society, 4, 4: 507-527.

Public Interest Advocacy Centre (2000). St. Christopher House: Urban CAP: Report of Local Residents and the Internet. Ottawa: Public Interest Advocacy Centre, November.

Reddick, A. and Boucher, C. (2002). Tracking the Dual Digital Divide. Ottawa: Ekos Research Associates Inc.

Reddick, A., Boucher, C., and Groseilleirs, M. (2000). The Dual Digital Divide. Ottawa: Public Interest Advocacy Centre.

Rideout, V. (2003). Continentalizing Canadian Telecommunications: The Politics of Regulatory Reform. Montreal: McGill-Queen's University Press. (2002/3). "Digital Inequalities in Eastern Canada." The Canadian Journal of Information and Library Sciences 27, 2: 3-31.

(forthcoming). "Community Visions of the Information Society with Canadian Exemplars." Javnost: The Public.

Statistics Canada (2004). The Daily for: 2004-07-08 (from: godfrey@ @stcwww.diss.statcan.ca)

Wellman, B. and Gulia, M (1998). "Net Surfers don't ride alone: virtual communities as communities", in (Eds.) P. Pollock \& M. Smith, Communities in Cyberspace. London: Routledge, pp. 187-194.

Warschauer, M. (2003). Technology and Social Inclusion: Rethinking the Digital Divide. Cambridge, Massachusetts: MIT Press. 